\title{
A comparison of erect weight-bearing and non-weight-bearing radiography of the cervical spine in non-trauma patients
}

\author{
Bimali S. Weerakoon*, Nimali N. Karunaratne, Winitha S. Jayasundara \\ Department of Radiography/Radiotherapy, Faculty of Allied Health Sciences, University of Peradeniya, Sri Lanka
}

\begin{abstract}
Introduction: Various positioning techniques are utilized to enhance the visualization of lower cervical vertebrae on lateral radiographs. However, the effectiveness of these techniques still remains unclear. This study was conducted to determine the effect of the weight-bearing (WB) technique in visualizing lower cervical vertebrae and cervicothoracic junction (C7-T1) on standing lateral cervical radiographs of adult non-trauma patients. The study was conducted using both computed radiography $(C R)$ and digital radiography (DR) systems.

Methods: Forty-four CR (29 WB and 15 non-WB - NWB) and 61 DR (26 WB and 35 NWB) lateral C-spine radiographs were prospectively evaluated to assess the visible number of cervical vertebral bodies and C7-T1 junction. The instructions given by the radiographer to the patient for the imaging procedure were also assessed on the Likert scale (very good, good, fair, poor, very poor).

Results: There was no significant difference $(p>0.05)$ in the visualization of the number of vertebral bodies between the two techniques of WB and NWB for CR or DR. Further, no significant relationship $(p>0.05)$ was observed between the WB technique and the visualization of C7-T1 junction in DR systems. However, a significant difference was identified for $C R(p=0.012)$. The instruction given to the patient significantly correlated with the visibility of the lower $C$-spine region within each group of WB and NWB in both imaging systems.

Conclusions: The visibility of the number of vertebral bodies in the lower C-spine region in either CR or DR systems did not demonstrate any enhancement with the WB technique. Regardless of the imaging system or techniques used, adequate instructions given to the patient before and during the imaging procedure of C-spine lateral radiography demonstrated a significant improvement in visualizing the lower C-spine region. In this preliminary study, the application of erect WB radiography technique in evaluating the lower cervical region of adult non-trauma patients gives limited advantage.

Keywords: Cervical spine, radiography, computed radiography, digital radiography, cervicothoracic junction, weight-bearing technique
\end{abstract}

\section{INTRODUCTION}

Although advanced imaging technologies are widely available, the lateral cervical spine radiograph remains the initial standard radiographic assessment for any type of cervical spinal injuries (1-3). It is a readily available, simple, and cost-effective radiographic examination (2). An adequate lateral $\mathrm{C}$-spine radiograph must demonstrate all seven cervical vertebrae (C1-C7), including the cervicothoracic junction (C7-T1), where $9-18 \%$ of cervical injuries occur $(1,4,5)$. Demonstration of lower cervical vertebrae is extremely important to avoid misdiagnosis of cervical

*Corresponding author: Bimali S.Weerakoon, Department of Radiography/ Radiotherapy, Faculty of Allied Health Sciences, University of Peradeniya,

Peradeniya 20400, Sri Lanka. E-mail: bsw888@ahs.pdn.ac.lk

Submitted: 16 February 2021/Accepted: 26 April 2021

DOI: https://doi.org/10.17532/jhsci.2021.1261 spinal injuries $(1,4)$. According to the literature, $37-72 \%$ of cervical spine radiographs do not adequately visualize the lower cervical region $(2,4,6)$. In such cases, alternative or supplementary radiographs such as Swimmer's view with additional exposure $(1,2,7)$ or computed tomography $(\mathrm{CT})$ with higher exposure (8) and higher cost are necessary for the adequate visualization of the lower cervical vertebrae. However, Swimmer's view is not recommended when trauma is suspected $(1,2,7)$. Cervical spine radiographs have been mostly replaced by CT as it is significantly sensitive in identifying fractures. When performing a CT cervical spine, the availability of multiplanar reformatting and interactive viewing facilities should be ensured. Magnetic resonance imaging is prescribed when neurological signs and symptoms related to the cervical spine present or evaluate new or increasing radiculopathy $(3,9)$. However, it is essential to highlight that still there are few readily available CT and MRI machines in Sri Lanka. 
According to the literature, neck length, body mass index (BMI), and shoulder density are the leading causes for inadequate visualization of the lower cervical spine on lateral radiographs (4). The density of the shoulders limits the complete visualization of the lower cervical spine and the C7-T1 junction through superimposition. To maximize the visualization of image details, it is mandatory to have adequately relaxed and depressed shoulders $(1,3,5)$. Further, proper instructions to the patient before and during the imaging procedure are essential to maintain an accurate patient positioning, thereby produce a good quality radiograph (2). There are various positioning techniques used for lateral cervical radiography in clinical practice, and there is no specific consensus regarding the optimum positioning (7). The standing C-spine lateral radiography can be mainly performed with four positioning techniques: by asking the patient to relax their shoulders downwards against the vertical bucky with arms by the side or by asking the patient to relax their shoulders downwards and forward as much as possible or by asking the patient to hold their arms behind the back with shoulders downwards and pull down as low as possible or by asking the patient to hold a weight in each hand if they are capable (10-12). Although standing weight-bearing (WB) positioning is recommended, its exact correspondence to the visualization of the lower cervical spine remains unclear. Therefore, this study was conducted to determine the effect of the WB positioning technique in visualizing lower cervical vertebrae and C7-T1 junction on standing lateral cervical radiographs of adult non-trauma patients. With the advancement of technology, digital radiography (DR) and computed radiography (CR) have become more popular than film-screen radiography. Even though with the latest technology, the quality of any radiograph depends on accurate patient preparation, positioning, and selection of appropriate exposure factors $(13,14)$. In this study, both CR and DR systems were used as a comparison. The results of this study will be useful in providing evidence-based education, which is very significant and essential in clinical practice.

\section{METHODS}

This prospective study was conducted in two CR and two DR units at three teaching hospitals in Sri Lanka over a period of 3 months. The study was conducted according to the standard departmental patient positioning practice and clinical protocols.

Based on non-probability purposive sampling, the study included all patients referred to lateral C-spine radiographs within the age range 15-65 years. Un-corporative patients, trolley patients, trauma patients, and patients with severe pain or a history of surgery in head, neck, and shoulder regions were excluded from the study. The study included only the first radiographs taken at any time, and repeat radiographs were excluded from the study. The study was approved by the Ethics Review Committee of the Faculty of Allied Health Sciences, University of Peradeniya, Sri Lanka (AHS/ERC/2019/049a) and informed consent was obtained from all the participants.

Before the imaging procedure, age, height, weight, midline neck length $(\mathrm{MNL}=$ upper margin of the hyoid bone to the jugular notch), and lateral neck length $(\mathrm{LNL}=$ mandible angle to the mid-portion of the ipsilateral clavicle) of each participant were recorded.

Based on the inclusion criteria, a total of $105 \mathrm{C}$-spine radiography procedures (Table 1) were included in the study. All the images were collected following the routine imaging procedure without any modification. The average exposure parameters for the procedures were ranged between 65 and $72 \mathrm{kVp}, 0.1-0.14 \mathrm{~ms}$, and $150 \mathrm{~mA}$. All the radiographs were obtained with the $150 \mathrm{~cm}$ fixed source-to-image detector distance and tube centering at the level of C4-C5. For the imaging procedure, the patients were instructed to stand with the feet slightly apart and place either shoulder against the vertical bucky. The median sagittal plane was adjusted to be parallel with the image receptor. The chin was extended, and the shoulders were depressed either by WB or non-weight-bearing non-WB (NWB) technique (Figure 1). Two water-filled cans weighing $4 \mathrm{~kg}$ were available in all the units for routine WB technique. The patient was instructed to hold each can in the WB technique. Two NWB positioning techniques were utilized to depress the shoulders and these two were simply relaxing the shoulders downwards against the vertical bucky with arms by the side or holding the arms behind the back with shoulders downwards and pull down as low as possible.

The investigators graded the radiographer's instructions for imaging procedure on the Likert scale (very good, good, fairly poor, very poor) based on their observations according to a pre-designed criterion (breathing, WB, or positioning of the arms/neck and movement instructions)

All the radiographs were visually evaluated for adequacy of exposure factors and artifacts by the investigators who have more than 5 years of experience in the radiography field. Adequate exposure is demonstrated by the clear visualization of margins of bony vertebrae, air column, and soft tissues (2). The radiographs were examined for the artifacts caused by the patient movements, double exposure, and radiopaque objects. Only the radiographs with adequate exposure factors, sufficient anatomical coverage, and the absence of artifacts were included in this study. The visibility of the number of vertebral bodies from top to bottom and the visibility of the C7-T1 junction on each radiograph were compared for the two positioning techniques. When counting, if any of the vertebral bodies were not completely visible, they were considered as "not visible." If the C7-T1

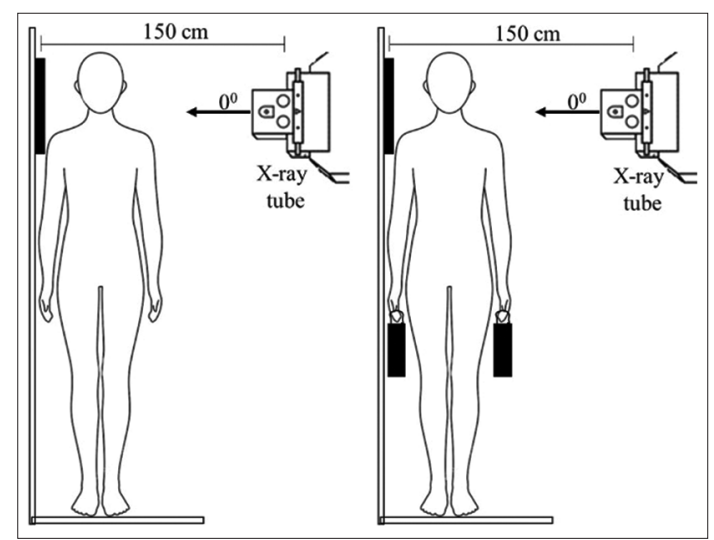

FIGURE 1. Positioning for the lateral C-spine radiography. (a). Non-weightbearing technique (b). Weight-bearing technique. 
TABLE 1. Demographic characteristics of the participants.

\begin{tabular}{|c|c|c|c|c|c|c|c|}
\hline \multirow[t]{2}{*}{ Characteristics } & \multirow{2}{*}{$\begin{array}{c}\text { Total population } \\
\text { mean (SD) }\end{array}$} & \multicolumn{3}{|c|}{$\mathrm{CR}$} & \multicolumn{3}{|c|}{$\mathrm{DR}$} \\
\hline & & With weight & Without weight & $p$ & With weight & Without weight & $p$ \\
\hline No. of patients & 105 & 29 & 15 & - & 26 & 35 & -- \\
\hline Age & $50.45(10.19)$ & $52.62(8.59)$ & $50.80(7.64)$ & 0.56 & $46.38(10.98)$ & $51.51(11.25)$ & $0.04^{*}$ \\
\hline $\mathrm{BMI}$ & $25.54(4.41)$ & $25.67(3.63)$ & $27.05(4.40)$ & 0.27 & $25.56(5.55)$ & $24.76(4.03)$ & 0.52 \\
\hline MNL & $7.96(1.46)$ & $8.53(1.39)$ & $7.80(1.47)$ & $0.04^{*}$ & $7.95(1.27)$ & $7.56(1.56)$ & 0.30 \\
\hline LNL & $10.70(1.15)$ & $10.83(1.08)$ & $10.77(1.16)$ & 0.46 & $10.40(1.18)$ & $10.79(1.18)$ & 0.21 \\
\hline Gender & $18 / 87$ & $5 / 24$ & $4 / 11$ & 0.46 & $3 / 23$ & $6 / 29$ & 0.72 \\
\hline
\end{tabular}

${ }^{*} p<0.05$. NWB: Non-weight-bearing, WB: Weight-bearing, LNL: Lateral neck length, MNL: Midline neck length, BMI: Body mass index, DR: Digital radiography, CR: Computed radiography

junction is partially visible, it was categorized as "slightly visible" (15).

The data obtained from CR and DR systems were analyzed separately. Descriptive statistics (mean $+\mathrm{SD}$ ) were used to analyze continuous variables, including the number of visible vertebrae. The normal distribution of the data was verified using Kolmogorov-Smirnov (if the sample size is $>30$ ) and Shapiro-Wilk tests (if the sample size is <30). Comparison of continuous variables between the two groups was conducted by Mann-Whitney U test (with non-normal distribution) and Student's t-test (with normal distribution). Comparison of categorical variables was made with the Chi-square test. Spearman rank correlation analysis was performed to identify the correlation between different variables and the visibility of the number of $\mathrm{C}$-spine vertebrae and C7-T1 junction. The testing was done as two-tailed, and an alpha value of 0.05 was set as the significant value.

\section{RESULTS}

The study sample consisted of 105 volunteers with a mean age of $50.45( \pm 10.19)$ years. There were $44(41.90 \%)$ CR and $61(58.10 \%)$ DR radiographs including 87 (82.90\%) female and 18 male (17.1\%) participants. Altogether, $55(52.38 \%)$ examinations performed with WB and 50 (47.62\%) examinations performed with NWB techniques (Table 1). The majority of the examinations (66, $62.90 \%$ ) were requested due to the indication of neck pain (Figure 2). The results of evaluating the given instructions in each type of imaging system and the techniques applied are displayed in Figure 3. Table 1 illustrates the demographic characteristics of the study participants and their comparison between WB and NWB techniques. Concerning MNL variable in $\mathrm{CR}$ imaging and age variable in $\mathrm{DR}$ imaging, there was a significant difference between the two groups of participants in WB and NWB. Table 2 demonstrates the correlation between the different variables with the visibility of the number of vertebrae and C7-T1 junction for the two positioning techniques, $\mathrm{WB}$ and $\mathrm{NWB}$, of $\mathrm{CR}$ and $\mathrm{DR}$ imaging. According to the results, MNL and LNL demonstrated a significant correlation $(p>0.05)$ with the visibility of the C7-T1 junction when performing the WB technique in CR imaging. Further, there was a significant correlation $(p>0.05)$ between the visibility of the number of vertebrae and BMI when performing the WB technique in DR imaging. The instructions given to the patients demonstrated a significant correlation $(p>0.05)$ with the visibility of the number of vertebrae and C7-T1 junction in both WB and NWB techniques of CR and DR imaging.

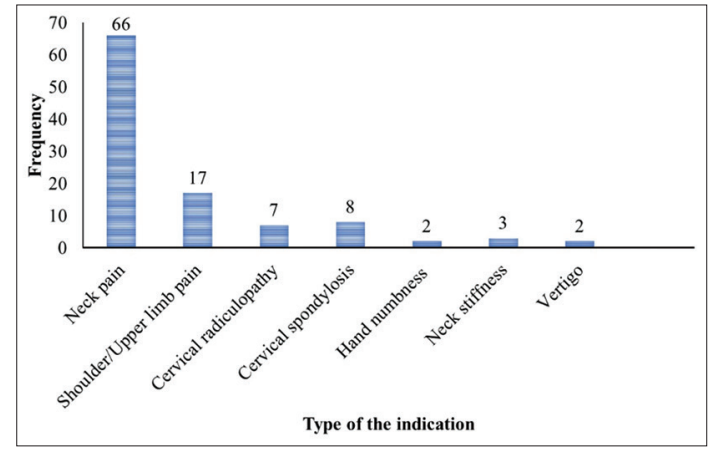

FIGURE 2. Frequency of the indication for C-spine lateral radiography.

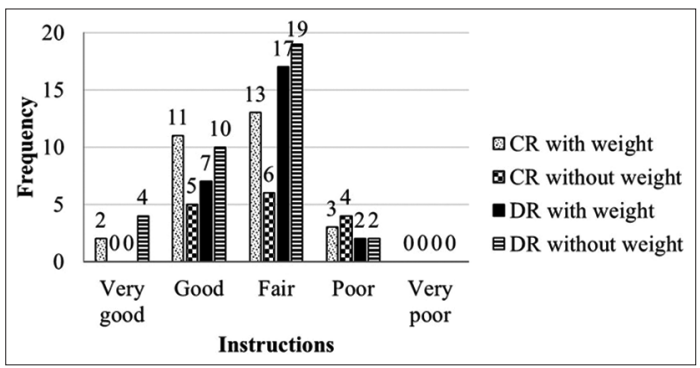

FIGURE 3. Evaluation of the given instructions to the patient before and during the imaging procedure of C-spine lateral radiography in each type of weight-bearing and non-weight-bearing positioning technique.

As demonstrated in Table 3, there was no statistically significant difference $(p>0.05)$ in the visualization of the number of vertebral bodies between the two techniques of WB and NWB in either CR or DR radiographs. However, according to Table 4, there was a statistically significant difference $(p<0.05)$ in the demonstration of C7-T1 junction between the two techniques of WB and NWB for CR radiographs.

\section{DISCUSSION}

Repetition of the radiographs may increase the unnecessary radiation exposure both to the patient and staff while increasing the workload and leading to the wastage of resources (2). The leading cause for the repetition of the $\mathrm{C}$-spine lateral radiograph is the inadequate visualization of the lower $\mathrm{C}$-spine region, including the C7-T1 junction. Radiographers and researchers suggest various strategies and positioning techniques to overcome this challenge for the non-trauma conditions $(4,16,17)$. Previous studies have identified the effectiveness of Swimmer's view $(1,4,17)$ and supine oblique view (17) in the visualization of the lower C-spine region. Certain literature suggests that there is an impact of arm traction on the visibility of the cervical region in radiography for the 
TABLE 2. Correlation between the different variables and the visibility of lower $\mathrm{C}$ spine region in the two positioning techniques of WB and NWB.

\begin{tabular}{|c|c|c|c|c|}
\hline $\begin{array}{l}\text { Imaging } \\
\text { method }\end{array}$ & Variable & $\begin{array}{l}\text { Positioning } \\
\text { technique }\end{array}$ & $\begin{array}{l}\text { Correlation } \\
\text { coefficient }\end{array}$ & $p$ \\
\hline \multirow[t]{20}{*}{$\mathrm{CR}$} & \multirow{2}{*}{$\begin{array}{l}\text { Age versus } \\
\text { number of visible } \\
\text { vertebrae }\end{array}$} & WB & 0.41 & 0.05 \\
\hline & & NWB & 0.18 & 0.52 \\
\hline & \multirow{2}{*}{$\begin{array}{l}\text { Age versus } \\
\text { C7-T1 Junction } \\
\text { visibility }\end{array}$} & WB & 0.28 & 0.14 \\
\hline & & NWB & 0.38 & 0.16 \\
\hline & \multirow{2}{*}{$\begin{array}{l}\text { BMI versus } \\
\text { number of visible } \\
\text { vertebrae }\end{array}$} & WB & 0.09 & 0.66 \\
\hline & & NWB & 0.30 & 0.27 \\
\hline & \multirow{2}{*}{$\begin{array}{l}\text { BMI versus } \\
\text { C7-T1 Junction } \\
\text { visibility }\end{array}$} & WB & 0.08 & 0.69 \\
\hline & & NWB & 0.31 & 0.26 \\
\hline & \multirow{2}{*}{$\begin{array}{l}\text { MNL versus } \\
\text { number of visible } \\
\text { vertebrae }\end{array}$} & WB & 0.46 & 0.13 \\
\hline & & NWB & 0.01 & 0.96 \\
\hline & \multirow{2}{*}{$\begin{array}{l}\text { MNL versus } \\
\text { C7-T1 Junction } \\
\text { visibility }\end{array}$} & WB & 0.45 & $0.01^{*}$ \\
\hline & & NWB & 0.22 & 0.44 \\
\hline & \multirow{2}{*}{$\begin{array}{l}\text { LNL versus no of } \\
\text { visible vertebrae }\end{array}$} & WB & 0.18 & 0.34 \\
\hline & & NWB & 0.30 & 0.28 \\
\hline & \multirow{2}{*}{$\begin{array}{l}\text { LNL versus } \\
\text { C7-T1 Junction } \\
\text { visibility }\end{array}$} & WB & 0.40 & $0.03^{*}$ \\
\hline & & NWB & 0.07 & 0.08 \\
\hline & \multirow{2}{*}{$\begin{array}{l}\text { Instruction } \\
\text { versus number } \\
\text { of visible } \\
\text { vertebrae }\end{array}$} & WB & 0.58 & $0.00^{*}$ \\
\hline & & NWB & 0.69 & $0.00^{*}$ \\
\hline & \multirow{2}{*}{$\begin{array}{l}\text { Instruction } \\
\text { versus C7-T1 } \\
\text { Junction visibility }\end{array}$} & WB & 0.53 & $0.00^{*}$ \\
\hline & & NWB & 0.68 & $0.00^{*}$ \\
\hline \multirow[t]{18}{*}{ DR } & \multirow[t]{2}{*}{$\begin{array}{l}\text { Age versus } \\
\text { number of visible } \\
\text { vertebrae }\end{array}$} & WB & 0.38 & 0.05 \\
\hline & & NWB & 0.15 & 0.38 \\
\hline & \multirow{3}{*}{$\begin{array}{l}\text { Age versus } \\
\text { C7-T1 Junction } \\
\text { visibility }\end{array}$} & WB & 0.26 & 0.21 \\
\hline & & & & 057 \\
\hline & & $\begin{array}{l}\text { NWB } \\
\text { WB }\end{array}$ & $\begin{array}{l}0.10 \\
0.41\end{array}$ & 0.04 * \\
\hline & \multirow{2}{*}{$\begin{array}{l}\text { BMI versus } \\
\text { number of visible } \\
\text { vertebrae }\end{array}$} & & & \\
\hline & & NWB & 0.18 & 0.32 \\
\hline & \multirow[t]{2}{*}{$\begin{array}{l}\text { BMI versus } \\
\text { C7-T1 Junction } \\
\text { visibility }\end{array}$} & WB & 0.43 & 0.07 \\
\hline & & NWB & 0.17 & 0.34 \\
\hline & \multirow{2}{*}{$\begin{array}{l}\text { MNL versus } \\
\text { number of visible } \\
\text { vertebrae }\end{array}$} & WB & 0.09 & 0.66 \\
\hline & & NWB & 0.26 & 0.13 \\
\hline & \multirow{3}{*}{$\begin{array}{l}\text { MNL versus } \\
\text { C7-T1 Junction } \\
\text { visibility }\end{array}$} & WB & 0.21 & 0.31 \\
\hline & & & & \\
\hline & & NWB & 0.15 & 0.41 \\
\hline & \multirow{3}{*}{$\begin{array}{l}\text { LNL versus } \\
\text { number of visible } \\
\text { vertebrae }\end{array}$} & WB & 0.11 & 0.61 \\
\hline & & & & \\
\hline & & NWB & 0.20 & 0.25 \\
\hline & $\begin{array}{l}\text { LNL versus } \\
\text { C7-T1 Junction } \\
\text { visibility }\end{array}$ & WB & 0.22 & 0.27 \\
\hline
\end{tabular}

TABLE 2. (Continued)

\begin{tabular}{lllcc}
\hline $\begin{array}{l}\text { Imaging } \\
\text { method }\end{array}$ & Variable & $\begin{array}{l}\text { Positioning } \\
\text { technique }\end{array}$ & $\begin{array}{c}\text { Correlation } \\
\text { coefficient }\end{array}$ & $p$ \\
\hline & & NWB & 0.17 & 0.34 \\
& $\begin{array}{l}\text { Instruction } \\
\text { versus no of } \\
\text { visible vertebrae }\end{array}$ & WB & 0.45 & $0.02^{*}$ \\
& & NWB & 0.48 & $0.00^{*}$ \\
& Instruction & WB & 0.34 & 0.07 \\
& versus C7-T1 & & & \\
Junction visibility & & & \\
& & NWB & 0.46 & $0.00^{*}$ \\
\hline
\end{tabular}

${ }^{*} p<0.05$. NWB: Non-weight-bearing, WB: Weight-bearing, LNL: Lateral neck length, MNL: Midline neck length,

BMl: Body mass index

TABLE 3. Comparison of the mean number of vertebral bodies visible between the two positioning techniques of WB and NWB.

\begin{tabular}{lccccccc}
\hline Variable & \multicolumn{3}{c}{ CR } & & \multicolumn{3}{c}{ DR } \\
\cline { 2 - 4 } \cline { 6 - 8 } & WB & NWB & $p$ & & WB & NWB & $p$ \\
\hline No. of & 6.90 & 6.60 & 0.18 & & 6.88 & 7.17 & 0.28 \\
vertebrae & $(0.67)$ & $(0.83)$ & & & $(0.77)$ & $(0.86)$ & \\
\hline
\end{tabular}

${ }^{*} p<0.05$. NWB: Non-weight-bearing, WB: Weight-bearing, DR: Digital radiography, CR: Computed radiography

TABLE 4. Comparison of visibility of C7-T1 junction between the two positioning techniques of WB and NWB.

\begin{tabular}{lccccc}
\hline $\begin{array}{l}\text { Positioning } \\
\text { Technique }\end{array}$ & $\begin{array}{c}\text { Clearly } \\
\text { visible }\end{array}$ & $\begin{array}{c}\text { Slightly } \\
\text { visible }\end{array}$ & $\begin{array}{c}\text { Not } \\
\text { visible }\end{array}$ & Total & $\begin{array}{c}p \text { (Pearson } \\
\text { Chi-squared) }\end{array}$ \\
\hline CR & & & & & \\
WB & 11 & 10 & 8 & 29 & \\
NWB & 3 & 1 & 11 & 15 & \\
Total & 14 & 11 & 19 & 44 & $0.01^{*}$ \\
DR & & & & & \\
WB & 07 & 06 & 13 & 26 & \\
NWB & 15 & 06 & 14 & 35 & \\
Total & 22 & 12 & 27 & 61 & 0.50 \\
\hline
\end{tabular}

${ }^{*} p<0.05$. NWB: Non-weight-bearing, WB: Weight-bearing, DR: Digital radiography, CR: Computed radiography

supine position (18-21). Toksoy et al. (4) found that traction can increase the field of view of the C-spine by approximately $9 \mathrm{~mm}$. Similar to the above, Bowe et al. (18) stated that the visibility of more than two-thirds of a vertebral body could be enhanced by arm traction. CT is recommended to perform when a conclusive diagnosis of the cervical injury is required urgently in adults (9). Using a WB positioning technique in $\mathrm{C}$-spine lateral radiographs as an adjunct to improve the visualization of the lower C-spine in adult non-trauma patients is suggested by some authors $(10,11)$. Application of a hand weight in the standing position is considered a simple technique that allows the lowering of shoulder girdles by applying equal forces directly onto the shoulder joints. However, to the best of our knowledge, there has been no study in the literature that evaluates the effectiveness of this WB positioning technique in enhancing the visualization of the lower C-spine region of adult non-trauma patients.

This current study was considered all the routine patients during the study period as the study sample based on its inclusion criteria. However, a statistically significant difference $(p<0.05)$ was found between the two groups of 
patients in the WB and NWB techniques in MNL variable in CR imaging and age variable in DR imaging (Table 1). Therefore, a correlation analysis (Table 2) was conducted to determine the effect of MNL and age on the visibility of the number of vertebrae and C7-T1 junction within the groups of WB and NWB. According to the results, MNL did not significantly $(p>0.05)$ affect the number of visible vertebrae in either WB or NWB groups. However, there was a significant correlation between MNL versus visibility of C7-T1 junction in the CR WB group. According to the literature, neck length is a major anatomic feature leading to an insufficient view of the lower C-spine region (4). Therefore, the difference of the MNL variable between the two groups of patients in the WB and NWB techniques may affect the comparison of this study within the CR imaging systems. Furthermore, age did not affect the visibility of the C-spine in either WB or NWB group in DR imaging as shown in Table 2. Therefore, although the age variable was different between the two groups of patients in the WB and NWB techniques in DR imaging, it did not affect the comparison of this study. According to Table 2, LNL and BMI demonstrated a significant correlation with the visibility of the cervical region in the WB technique. However, as shown in Table 1, there is no significant difference of these variables between the two groups of patients in the WB and NWB techniques. Therefore, those two variables did not affect the outcome of this study.

Regardless of the imaging system or techniques used, it is essential to give adequate instructions to the patient before and during the imaging procedure of C-spine lateral radiography as it can enhance the clear visualization of the lower C-spine region (2). It is believed that suspended respiration on a full exhalation able to lower the shoulders (10). Further, it has been noted that patients frequently hunch their shoulders to hold the weights firmly while keeping them still (12). Therefore, a careful explanation is very much essential, especially in the WB technique. A significant correlation between the given instruction and the visibility of lower C-spine region in both WB and NWB groups was found in this study with both imaging systems (Table 2). This highlights the idea that the instructions influence the success of examinations for both WB and NWB, CR and DR. The study carried out by Bowe et al. (18) with different traction methods demonstrated that manual traction accompanied by proper breathing instructions could improve the visualization of C-spine on lateral radiographs.

According to the results of this study, there was no significant relationship observed between the WB technique and the visualization of the number of vertebral bodies in either CR or DR imaging systems. Further, no significant association was observed between the WB technique and the visualization of the C7-T1 junction in DR systems. However, the WB positioning technique significantly improved the ability to visualize the C7-T1 junction only in CR systems with a $p$ value of 0.01 in this study. This observation could be attributed to several factors. First, there was a significant difference $(p<0.05)$ in the MNL variable between the two groups of patients in WB and NWB positioning techniques in CR imaging systems. Second, out of all NWB techniques in CR imaging, 53.33\% were done with the positioning technique of just relaxing the shoulders downwards against the vertical bucky with arms by the side. The above NWB positioning technique might have been an ineffective technique to visualize the lower cervical region. However, this should be further investigated.

There are a few limitations in this study. First, the low number of participants in each subgroup might have caused the lack of power of the study. Therefore, it is suggested to conduct the study with a larger sample size to investigate the true association between the variables. It is also suggested to perform the study as a randomized controlled trial which could provide better evidence and make the results more robust. Second, this study tried to compare the real-life situation in clinical practice. Ideally, two positioning techniques should have been performed in the same patient to reduce the intrapersonal variability during the comparison. Nevertheless, in this study, different patients have been used for the comparison. Thirdly, bi-acromial breadth (horizontal distance across the shoulders measured between the acromia bony points) of the patient could affect the visibility in the lower C-spine region. However, this study did not collect data related to the above variable. Nevertheless, to the best of our knowledge, this study is the first attempt that evaluates the effectiveness of the WB positioning technique of adult non-trauma patients in C-spine lateral radiography.

\section{CONCLUSIONS}

The standing WB technique did not exhibit any benefit in enhancing the visibility of the number of vertebral bodies in the lower C-spine region in either CR or DR systems. Regardless of the imaging system or techniques used, adequate instructions given to the patient before and during the imaging procedure of C-spine lateral radiography demonstrated a significant improvement in visualizing the lower $\mathrm{C}$-spine region. Based on the findings of this preliminary study, the application of erect WB radiography technique in the evaluation of the lower cervical region of adult nontrauma patients gives limited advantage. However, further investigations are recommended with a larger sample size to confirm the results.

\section{COMPETING INTERESTS}

All authors would like to disclose that they have no conflicts of interest related to this study.

\section{ACKNOWLEDGMENT}

The authors would like to thank all three teaching hospitals in this study for granting permission to collect data. The authors also wish to give their sincere appreciation to all the patients who participated in this study and all the parties who contributed to complete this study successfully.

\section{REFERENCES}

1. Rethnam U, Yesupalan RS, Bastawrous SS. The Swimmer's view: Does it really show what it is supposed to show? A retrospective study. BMC Med Imaging 2008;8:2 https://doi.org/10.1186/1471-2342-8-2.

2. Shrestha $S$, Maharhan $S$, Khanal U, Humagain M. Evaluation of image quality in cervical spine lateral radiographs. J Chitwan Med Coll 2017;6(1):30-3. https://doi.org/10.3126/jcmc.v6i1.16652.

3. McDonald MA, Kirsch CF, Amin BY, Aulino JM, Bell AM, Cassidy RC, et al. ACR 
appropriateness criteria ${ }^{\circledR}$ cervical neck pain or cervical radiculopathy. J Am Coll Radiol 2019;16(5):S57-76.

4. Toksoy A, Bektas F, Eken C, Ceken K, Cete Y. Value of the swimming position and arm traction in visualizing the cervicothoracic junction over the standard lateral cervical X-ray. Int J Emerg Med 2010;3(2):85-90.

https://doi.org/10.1007/s12245-010-0159-y.

5. Rhea JT, Rao PM, Novelline RA. The normal cervical spine and its variations on plain radiography and computed tomography. Emerg Radiol 1998;5(1):13-28. https://doi.org/10.1007/bf02749122.

6. Wongwaisayawan S, Suwannanon R, Kaewlai R. Imaging of cervicothoracic junction trauma. Reports Med Imaging 2013;6(1):11-27.

https://doi.org/10.2147/rmi.s28865.

7. Morimoto Y, Shigematsu H, Iwata E, Tanaka M, Okuda A, Masuda K, et al. Evaluating cervical sagittal alignment in cervical myelopathy: Are sitting cervical radiographs and standing whole-spine radiographs equally useful? Glob Spine J 2019;9(6):591-7. https://doi.org/10.1177/2192568218811841.

8. Mettler FA, Huda W, Yoshizumi TT, Mahesh M. Effective doses in radiology and diagnostic nuclear medicine: A catalog. Radiology 2008; 248:254-63. https://doi.org/10.1148/radiol.2481071451.

9. Investigation for Injuries to the Cervical Spine in Patients with Head Injury; 2020 [Last accessed on 2021 April 10]. Available from: http://www.pathways.nice.org.uk/ pathways/head-injury.

10. Whitley AS. Clarks Positioning in Radiography. $13^{\text {th }}$ ed. Boca Raton, Florida: CRC Press; 2015.

11. Long BW. Merrill's Atlas of Radiographic Positioning and Procedures. Vol. 1. 2003. Missouri SIL: MAORP and RP.

12. Carver E, Barry C. Medical Imaging: Techniques, Reflection and Evaluation. $2^{\text {nd }}$ ed. Amsterdam, Netherlands: Elsevier; 2012.

13. Rushton VE, Horner K, Worthington HV. The quality of panoramic radiographs in a sample of general dental practices. Br Dent J 1999;186:630-3

https://doi.org/10.1038/sj.bdj.4800182a.

14. Peretz B, Gotler M, Kaffe I. Common errors in digital panoramic radiographs of patients with mixed dentition and patients with permanent dentition. Int $\mathrm{J}$ Dent 2012;2012:584138.

https://doi.org/10.1155/2012/584138.

15. Davies AM, Pettersson H. The WHO manual Radiographic Anatomy and Interpretation. In: Ostensen H, Pettersson H, editors. World Health Organization in Collaboration with the International Society of Radiology. Geneva, Switzerland: World Health Organization; 2002. p. 66-71.

16. Carr B, Grahovac S, Stiell I. Visualization of C, $-\mathrm{TI}$ on portable lateral cervical spine radiographs using a lead-lined acrylic filter. Acad Emerg Med 1995;2:610-4. https://doi.org/10.1111/j.1553-2712.1995.tb03598.x.

17. Ireland AJ, Britton I, Forrester AW. Do supine oblique views provide better imaging of the cervicothoracic junction than Swimmer's views? Emerg Med J 1998;15(3):151-4. https://doi.org/10.1136/emj.15.3.151.

18. Bowe CT, Burton JH, Chandler RC, Davidson RM. The effect of arm traction on the adequacy of cross-table lateral cervical spine radiographs. J Trauma 2003;55(4):800-1. https://doi.org/10.1097/01.ta.0000082159.89691.15.

19. Boger D, Ralls PW. New traction device for radiography of the lower cervical spine. Am J Neuroradiol 1981;2:467-9.

20. Norris CS, Silva WE, Dodson TF, Darrow J. Shoulder harness traction for roentgenographic assessment of the cervical spine. Arch Surg 1986;121:452-5. https://doi.org/10.1001/archsurg.1986.01400040090014.

21. Truong VT, Al-Shakfa F, Boubez G, Shedid D, Yuh SJ, Wang Z. Enhanced visualization of the cervical vertebra during intraoperative fluoroscopy using a shoulder traction device. Asian Spine J 2020;14:502-6.

https://doi.org/10.31616/asj.2019.0255. 